\title{
Biomarkers and Prevention Research Branch
}

National Cancer Institute

\section{Source}

National Cancer Institute. Biomarkers and Prevention Research Branch. NCI Thesaurus.

Code C19623.

The Branch plans and conducts intramural research aimed at identifying new tools for the early detection of cancers and developing cancer intervention agents. (from Division of Cancer Prevention and Control 1994 Annual Report) 